\title{
REVOLUÇÃO COMO NEGAÇÃ̃O DA NEGAÇÃO? CONSIDERAÇÕES SOBRE A RECEPÇÃO MARXIANA DE HEGEL ${ }^{1}$
}

\author{
Christian Iber $^{2}$
}

\begin{abstract}
Resumo:
A contribuição se articula em três momentos. Na primeira parte apresenta-se a problemática do emprego feito por Marx do conceito hegeliano da negação da negação pela revolução proletária na crítica da economia política. A segunda parte discute a vinculação crítica de Marx ao conceito da negação da negação de Hegel no excurso referente à crítica da dialética e filosofia hegelianas em geral dos Manuscritos econômico-filosóficos (Manuscritos parisienses), de 1844, e precisamente em quatro itens: em primeiro lugar, mostra-se, em que Marx se junta à posição de Feuerbach e em que ele vai além dela. Em segundo lugar, delineia-se a crítica de Marx ao sistema hegeliano no que concerne à Fenomenologia do Espírito, à Ciência da Lógica e à passagem para a natureza e a filosofia real. Em terceiro lugar, discute-se a compreensão que Hegel e Marx têm com relação a negatividade, exteriorização e alienação e, em quatro lugar, contorna-se a posição própria de Marx. A terceira parte faz alusão a uma interpretação alternativa ao mito da negação da negação da transformação revolucionária da sociedade capitalista em Marx mais tardiamente.
\end{abstract}

Palavras-chave: Negação da negação. Exteriorização. Alienação. Revolução.

\section{REVOLUTION AS NEGATION OF THE NEGATION? ON MARX'S RECEPTION OF HEGEL}

\begin{abstract}
:
The article has three parts. The first part examines the problem of Marx' use of Hegel's concept of negation of negation for the proletarian revolution in the Critique of the Political Economy. The second part discusses Marx' critical reception of Hegel's concept of the negation of negation in the excursus to the critique of hegelian dialectic and philosophy in general of Economic and Philosophic Manuscripts (= Paris Manuscripts) of 1844, namely in four sections: Firstly it is shown in what Marx follows Feuerbach's position and in what he transcends it. Secondly Marx' critique on Hegel's system concerning the Phenomenology of the Spirit, the Science of Logic and the transition to nature and real philosophy is outlined. The third item discusses Hegel's and Marx' understanding of negativity, externalisation and alienation and fourthly Marx' own position is outlined. The third part suggests an alternative interpretation of the myth of negation of negation of the revolutionary transformation of capitalist society in later Marx.
\end{abstract}

Keywords: Negation of negation. Externalisation, Alienation. Revolution.

1 Uma versão alemã do artigo será publicada na revista: Allgemeine Zeitschrift für Philosophie 43.3/2018. Eva Schürmann, Harald Schwaetzer (Orgs.). Karl Marx. Organização do caderno: Lore Hühn. Stuttgart-Bad Cannstatt: Frommann-holzboog.

2 Doutor em Filosofia da Livre Universidade de Berlim. Atualmente é pesquisador do Programa Nacional de Pós-Doutorado (PNPD) na Pontifícia Universidade Católica do Rio Grande do Sul (PUCRS / Brasil). E-mail: christian.iber@yahoo.de 
Na sua crítica da economia política, Marx emprega dois tipos diversos de dialética que ele delineia no recurso à filosofia de Hegel: em primeiro lugar, a dialética como método da apresentação e, em segundo lugar, a dialética da história. Em seguida, a partir desses dois tipos de dialética, discute-se criticamente apenas a última, porque somente com respeito a ela se faz sentir em Marx uma relação afirmativa a Hegel. No que diz respeito à dialética como método da apresentação do modo de produção capitalista, a implantação de categorias da lógica hegeliana, a fim de proporcionar à apresentação do conceito de capital uma clareza maior, pressupõe, primeiramente, a separação crítica daquilo que Marx considera o mistificante e o racional nela, e, em segundo lugar, o próprio conceito de capital. Pois da instrumentalização metódica de categorias hegelianas não resulta o conceito da Coisa, mas em toda a ocasião sua apresentação mais concisa. ${ }^{3}$

\section{A caracterização de Marx da revolução como negação da negação na crítica da economia política}

No quatro item, "Tendência histórica da acumulação capitalista" do capítulo 24 "A assim chamada acumulação primitiva" do primeiro livro de $O$ Capital num lugar central surge a figura hegeliana do pensar da negação da negação. ${ }^{4} \mathrm{O}$ conceito da primeira negação entende a expropriação da propriedade privada que se baseia no trabalho próprio e, com isso, a passagem para a apropriação e a exploração do trabalho alheio pela propriedade privada nos meios de produção. A segunda negação representa a expropriação dos expropriadores.

Com a figura do pensar da negação da negação, Marx descreve, em primeiro lugar, a mudança que é peculiar à sociedade capitalista - a expropriação progressiva de pequenos proprietários e sua transformação em trabalhadores assalariados -, sendo que ele, em segundo lugar, apreende essa mudança como passagem da forma capitalista da sociedade em uma outra, mais alta. Marx emprega, portanto, o conceito da negação da negação, a fim de caracterizar a revolução proletária. Ele exprime aquilo que segue de modo racional da intelecção na incompatibilidade do modo de produção capitalista com os interesses dos

3 Em ambas as versões da dialética em Marx tardio, Quante vê uma vinculação positiva sem ruptura a Hegel (cf. Michael Quante. 'Die Logik ist das Geld des Geistes'. Zur Rezeption der Hegelschen Logik im Linkshegelianismus und der Kritik der politischen Ökonomie“, [,"A lógica é o dinheiro do espírito“. Para a recepção da lógica hegeliana na esquerda hegeliana e da crítica da economia política”] In: C. Wirsing, A.F. Koch, F. Schick. K. Vieweg (Orgs.). Hegel - 200 Jahre Wissenschaft der Logik, Hamburg: Meiner, 2014, 429-431).

4 Cf. Karl Marx. O Capital. Crítica da economia política. Livro I. O processo de produção do capital. Tradução Rubens Enderle. São Paulo: Boitempo 2013 (E-Book), 1013/1493.

\begin{tabular}{|c|c|c|}
\hline Qevista Dialectus & Ano 5 & n. 12 \\
\hline
\end{tabular}


trabalhadores, considerando que o racional impõe-se historicamente sem falta e apresenta esse processo de forma otimista como "necessidade de um processo natural". 5 Nessa passagem Marx não exagera na dose ao aproximar-se da lógica hegeliana? Com efeito, aqui a lógica da negação da negação não tem mais o caráter de uma lei universal da história. Ela exprime, antes, a intelecção no negativo do capitalismo existente e tira disso a consequência da sua negação prática. ${ }^{6}$ Todavia, já seria oportuno uma indicação para o fato que não é a lógica da negação da negação, mas a luta necessária da classe trabalhadora contra o modo de produção capitalista, com a qual o racional se abre como caminho na efetividade.

Como disse, também ainda em $O$ Capital Marx atribui a negação da negação à „,necessidade de um processo natural“. Os Manuscritos parisienses, de 1844, tornam saliente que entre a denominação do processo histórico como processo natural e a negação da negação há uma conexão. A história até agora é compreendida como história natural do homem. Com o conceito da negação da negação Marx denomina nos Manuscritos parisienses e também ainda em $O$ Capital não propriamente um processo revolucionário da transformação, que parte dos sujeitos atuantes que consideram sua luta contra o capitalismo necessária, mas ele torna com ele da libertação do processo histórico como processo natural mesmo um processo natural que os sujeitos atuantes apenas executam. Na tradição do movimento dos trabalhadores e do marxismo essa tendência de uma interpretação teleológica da história na crítica de Marx ao capitalismo, segundo a qual o capitalismo alveja sua autossuperação própria, por um lado, foi acolhida positivamente com respeito ao socialismo, por outro lado, negativamente com referência a seu colapso. ${ }^{7}$

A naturalização da história, que é desligada dos sujeitos, conduz ao pensamento de uma história que se processa automaticamente. Essa tendência da naturalização e da objetivação da história, que não se encontra em todos os lugares em Marx e contra a qual ele se defende mesmo no seu abandono de Feuerbach, está ligada a uma vinculação positiva a Hegel. Pode-se dizer que a relação positiva de Marx a Hegel, nesse sentido, permanece

5 Marx. O Capital. Livro I. São Paulo: Boitempo, 2013 (E-Book) (obs. 4), 1013, 1493.

6 A maneira de falar no posfácio à segunda edição de $O$ Capital. Livro I, que a "intelecção positiva do existente, inclui, ao mesmo tempo, a intelecção de sua negação, de seu necessário perecimento" (Marx. $O$ Capital. Livro I. São Paulo: Boitempo, 2013 (E-Book), 130/1493), não tem que ser compreendido assim que o caráter da negação é atribuído ao próprio decurso real da história, como Quante entende, mas que isso está ligado à intelecção no negativo do existente (cf. Quante. “„Die Logik ist das Geld des Geistes“ [“A lógica é o dinheiro do espírito"] (obs. 3), 424).

7 Para a crítica à concepção de Marx da supernova do desenvolvimento capitalista cf. Christian Iber. Elementos da teoria marxiana do capitalismo. Porto Alegre: Editora fi, 2013, 474-477.

\begin{tabular}{|c|c|c|c|c|}
\hline Rovista Dialectus & Ano 5 & n. 12 & Janeiro - Julho 2018 & p. $121-138$ \\
\hline
\end{tabular}


constante no decorrer dos anos. Um certo hegelianismo intacto se encontra também em Marx mais tardiamente.

No seu diagnóstico da expropriação dos expropriadores, Marx recorre em $O$ Capital à lei dialética que a quantidade se converte na qualidade. De acordo com um tipo de uma teoria da pressão de represamento a depauperização, que se torna sempre maior, deve se converter na indignação e revolta. ${ }^{8}$ Também no escrito A família sagrada ou crítica da crítica crítica, de 1845, a ação da autolibertação do proletariado se torna uma necessidade histórica. Ela não é uma ação livre da intelecção que pode ser posta em prática ou não. ${ }^{9}$ A naturalização da libertação da história até agora como história natural, da qual se distingue a história efetiva, tem sua origem na discussão de Marx com Hegel nos Manuscritos parisienses de 1844.

\section{A discussão de Marx com Hegel no excurso sobre Hegel dos Manuscritos parisienses $^{10}$}

\section{Recepção crítica da posição de Feuerbach}

Na sua crítica de Hegel nos anos 1839 até 1843, Feuerbach vê muito claro que, na sua filosofia, Hegel não sai do seu pensamento. ${ }^{11}$ Hegel seria um pensador que se supera no

8 “Com a diminuição constante do número de magnatas [...], aumenta a massa da miséria, da opressão, da servidão, da degeneração, da exploração, mas também a revolta da classe trabalhadora, que, cada vez mais numerosa, é instruída, unida, organizada pelo próprio mecanismo do processo de produção capitalista" (Marx. O Capital. Livro I. São Paulo: Boitempo, 2013 (E-Book) (obs. 4), 1013/1494).

$9 \quad$ No capítulo 4 desse escrito se diz: "não se trata do que esse ou aquele proletariado ou mesmo todo o proletariado se representa por enquanto como meta. Trata-se do que é e o que ele será forçado a fazer historicamente conforme esse ser" (MEW 2, 38). No capítulo 5 essa teleologia da história é corretamente rejeitada: "A história não faz nada. É antes o homem [...] que tudo isso faz, possui e luta; não é aproximadamente a 'história' que o homem usa como meio, a fim de impor - como que ela seria uma pessoa singular - suas finalidades, mas ela não é nada do que a atividade do homem que persegue seus fins" (MEW 2, 98). Na Ideologia alemã (1845/46) o comunismo é determinado como expressão de um movimento real na história: 'Nós denominamos 'comunismo' o movimento efetivo que suprassume o estado atual. As condições desse movimento resultam da pressuposição agora existente" (MEW 3, 35).

10 Fundamental aos Manuscritos parisienses são dois estudos: Ernst Michael Lange. Das Prinzip Arbeit [O princípio do trabalho], Frankfurt am Main/Berlin: Ullstein, 1980 e Michael Quante. Karl Marx, Ökonomischphilosophische Manuskripte. Kommentar von Michael Quante. Frankfurt am Main: Suhrkamp, 2009.

Cf. Ludwig Feuerbach. Zur Kritik der Hegelschen Philosophie, Vorläufige Thesen zur Reform der Philosophie [Para a crítica da filosofia hegeliana, teses provisórias para a reforma da filosofia] e Grundsätze einer Philosophie der Zukunft. [Princípios de uma filosofia do futuro]. Esses escritos se encontram em idem. Gesammelten Werk, vol. 9. Werner Schuffenhauer (Org.). Berlin 1927s.

\begin{tabular}{|c|c|c|c|c|}
\hline Rovista Dialectus & Ano 5 & n. 12 & Janeiro - Julho 2018 & p. $121-138$ \\
\hline
\end{tabular}


pensar, que no ir além do pensamento não chega na própria realidade. Sua filosofia vai em seguimento do programa de deduzir todo o conteúdo do pensar a partir do próprio pensar.

Não obstante, as "descobertas de Feuerbach" (20) ${ }^{12}$ contêm, de acordo com Marx, uma crítica pertinente à filosofia de Hegel, sobretudo na medida em que ele mostra que a filosofia de Hegel como execução pensante da religião é uma figura da alienação; contudo, seria necessário ulteriormente uma discussão com o próprio Hegel. Pois, primeiramente, a crítica neohegeliana da religião e de Hegel continua sendo do ponto de vista da filosofia hegeliana - Bruno Bauer e David Friedrich Strauß reduzem o homem como Hegel à autoconsciência - e, segundamente, Feuerbach teria contraposto sua posição própria como positivo que repousa sobre si mesmo ao idealismo de Hegel apenas "direta e imediatamente" (118). Ele teria rejeitado a figura hegeliana do pensar da negação da negação que se afirma como positivo e teria apreendido a negação da negação apenas negativamente como contradição da filosofia consigo mesma. Com isso, Feuerbach desconhece, segundo Marx, que com o princípio da negação da negação Hegel apreendeu adequadamente a essência do trabalho humano e a estrutura principal da história humana sob as condições da alienação. $\mathrm{O}$ potencial da figura hegeliana da negação da negação Marx gostaria de preservar numa concepção materialista da história (cf. 118s, 123).

Como prova da posição feuerbachiana que está circunscrita com os termos realismo, materialismo verdadeiro (teórico de sociedade) e naturalismo humanista, precisa-se da dialética hegeliana. A posição de Feuerbach do humanismo naturalista Marx não compreende tão-somente descritivamente mas normativamente que tem que ser primeiramente provada ou mediada. Marx assume, portanto, de Feuerbach e Moses Heß a concepção da essência genérica humana que teria que se efetivar de modo histórico. A figura hegeliana do pensar da negação da negação serve como localização do comunismo (= humanismo naturalista) no desenvolvimento histórico da essência genérica humana. Com ela supera-se a "história da geração do homem" (119), sua pré-história e história natural ${ }^{13}$ e se inicia sua "história efetiva" (118) como um sujeito pressuposto que Marx identifica com o positivo feuerbachiano. Marx se coloca a tarefa dupla de destrinchar, primeiramente, em que

12 Karl Marx. Manuscritos econômico-filosóficos. Tradução, apresentação e notas Jesus Ranieri. São Paulo: Boitempo, 2004. Em seguida, esse escrito é citado sem siglo.

13 "A história é a verdadeira história natural do homem" (128). O comunismo não é para Marx a meta e, com isso, o fim da história, mas a libertação do homem da sua história natural, quer dizer, da história sob as condições da alienação social (cf. Andreas Arndt., Karl Marx, Ökonomisch-philosophische Manuskripte. Kommentar von Michael Quante [recensão]. In: Hegel-Studien 45 (2010). Hamburg, Meiner: 2011, 207).

\begin{tabular}{|c|c|c|c|c|}
\hline Revista - Didectus & Ano 5 & n. 12 & Janeiro - Julho 2018 & p. 121-138 \\
\hline
\end{tabular}


consiste o déficit da filosofia hegeliana e, segundamente, em que residem seus potenciais produtivos.

\section{Crítica ao sistema hegeliano}

A crítica geral à filosofia de Hegel diz que ela seria uma forma espiritual da alienação. Marx afirma com referência a Hegel duas coisas distintas: (i) a filosofia de Hegel teria a alienação como tema geral. (ii) A filosofia de Hegel seria um pensar abstrato e, portanto, ela mesma uma forma da alienação. Sua determinação da essência do homem como essência pensante ou espiritual seria uma abstração "da natureza e do ser humano efetivo" (120). A lógica de Hegel seria a dimensão, na qual o espírito alienado, que se apreende de modo pensante, é fundamentado. Como indiferente frente a todo o conteúdo determinado, a lógica é ao mesmo tempo igualmente válida para cada conteúdo particular, do qual segue sua aplicabilidade universal. Da perspectiva do pensar abstrato da lógica, a natureza e o espírito aparecem como derivados do lógico. A lógica aparece, portanto, conforme Marx, como a dimensão originária metafísica da natureza e do espírito.

Com Feuerbach, Marx assume que a filosofia de Hegel como religião executada seria um modo de ser aí da alienação espiritual. A alienação espiritual mediada pela religião, que se baseia na alienação social do trabalho causada pela propriedade privada, é a que Feuerbach descreve com o conceito da projeção, a projeção das propriedades da essência humana em uma essência divina, à qual o homem está subordinado. Marx tinha a posição de que com Feuerbach a crítica da religião estaria consumada e via-se autorizado a transferir a crítica da religião para a crítica às relações sociais de dominação. A forma espiritual da alienação do homem na religião e na filosofia assenta na sua abstração real, na alienação social do trabalho, causada pela propriedade privada, e alveja a afirmação desse estado social. ${ }^{14}$ Nos Manuscritos parisienses não é mencionado a alienação política do homem em sua duplicação em citoyen e bourgeois, tematizada na Crítica da filosofia do direito de Hegel (1843) e no escrito Sobre a questão judaica (1843). A omissão da dimensão da alienação política dá ao esboço de 1844 um caráter abstrato. ${ }^{15}$

14 Sob a alienação espiritual Marx compreende o pensar ideológico que está sustentado pelo impulso da justificação da realidade efetiva e é, portanto, um pensar equivocado.

15 Antes de Marx no Discurso sobre a desigualdade (1775), Rousseau defendeu uma teoria da alienação. Ele constrói o estado natural do homem como padrão de medida normativo da alienação da sociabilidade. Não uma sociedade determinada, mas a sociabilidade em geral significa alienação. Rousseau faz assunções

\begin{tabular}{|l|l|l|l|l|}
\hline Ronista Dialectus & Ano 5 & n. 12 & Janeiro - Julho 2018 & p. 121-138 \\
\hline
\end{tabular}


Resumamos: a abstração que o pensar abstrato exerce, é, em primeiro lugar, basicamente uma abstração do homem efetivo e da natureza. Em segundo lugar, o pensar é pensar abstrato, na medida em que ele mesmo imita uma abstração real, e precisamente de forma distorcida. Marx quer agora mostrar que o pensar abstrato desencontra a tematização adequada da alienação real. Por conseguinte, ele quer reconduzir o conceito do espírito hegeliano ao homem efetivo e à natureza.

a. Fenomenologia do Espírito: O erro decisivo de Hegel seria que ele não estaria interessado na alienação prática real nem em sua eliminação efetiva na prática, mas transforma a alienação num estado de coisas teórico, nesse caso, ele aplica como"padrão de medida do mundo alienado" (121 [tradução minha]) apenas o homem alienado, o homem pensante. A pura oposição do sujeito e do objeto, dos homens e do mundo é tomada por Hegel como expressão da alienação do espírito pensante de si mesmo. Isso tem por consequência que não é criticado o caráter alienado da objetividade, mas a própria objetividade como alienação. ${ }^{16}$ Sob o título "o Saber absoluto" o capítulo conclusivo da Fenomenologia do Espírito alveja a "superação do objeto da consciência" (125 tradução minha), na qual a autoconsciência pensante na sua exteriorização objetiva se exterioriza a si mesmo, põe-se como objeto e, com isso, está junto de si mesmo no outro ${ }^{17}$, nesse caso Hegel comete o quid pro quo que, com a suprassunção pensante da objetividade da representação religioso-moral

essencialistas sobre o homem natural: autodeterminação e autarcia, amor à liberdade e à preguiça etc. A figura romântica da alienação e a suprassunção completa da alienação, que se encontra em Rousseau, Schiller, Hölderlin, Novalis, Friedrich Schlegel etc., em Marx inicial enraiza num essencialismo da essência genérica humana.

À história é atribuída a tarefa de colocar o homem desunido consigo em correspondência consigo. Como suprassunção da alienação o comunismo seria o "retorno do homem para dentro de si" (105 [tradução minha]). Na Ideologia alemã (1845/46) a fundamentação filosófica do comunismo por Feuerbach é submetida uma crítica. Na crítica da economia política, que é desenvolvida no anos de 1850, encontram-se apenas ainda rastros da teoria filosófica da alienação. Diferentemente, ao contrário, Mészáros que também em Marx tardio vê a teoria da alienação em ação (cf. István Mészáros. Marx’s Theory of Allienation. London 1970, 114s.).

16 "Suprassunção da alienação identificada com suprassunção da objetividade (um lado, nomeadamente desenvolvido por Feuerbach)“. Karl Marx. "Construção hegeliana da Fenomenologia”. In: MEW 3, 536).

17 No saber absoluto, a autoconsciência pensante se sabe no outro como ao mesmo tempo praticamente realizada. No capítulo conclusivo, sob "objeto" está entendida a reconciliação objetivamente representada da consciência religiosa de Deus e homem e, com isso, do homem consigo mesmo, que é realizada praticamoralmente na comunidade da consciência moral. Nos neohegelianos essa concepção forma o pano de fundo para a concepção de uma sociedade não alienada que Marx designa comunismo (cf. Andreas Arndt. Geschichte und Freiheitsbewusstsein. Zur Dialektik der Freiheit bei Hegel und Marx [História e consciência da liberdade. Para a dialética da liberdade em Hegel e Marx]. Berlin 2015, 58). Não carece de uma graça irônica que Marx coloca o comunismo no lugar do saber absoluto como „,dissolução verdadeira“ de todo o „conflito“ (105). Ele é a execução prática da insurreição teoricamente exigida das relações sociais alienadas e se sabe também disso.

\begin{tabular}{|l|l|l|l|l|}
\hline Q Povista Oialectus & Ano 5 & n. 12 & Janeiro - Julho 2018 & p. 121-138 \\
\hline
\end{tabular}


do mundo, o filósofo se representa ao mesmo tempo como dono do mundo, mas justamente apenas em pensamentos.

$\mathrm{Na}$ mera suprassunção mental da objetividade, que deixa existir a realidade existente não alterada, reside ao mesmo tempo também o positivismo acrítico e falso do idealismo de Hegel que é ao mesmo tempo um criticismo aparente (cf. 139). A crítica da consciência de Hegel dá a entender para Marx que, conforme sua essência, a efetividade não é algo alienado ao homem, mas que ela somente parece ser assim. Vale, portanto, compreender que ela [a efetividade] lhe corresponde propriamente e conforme sua essência não é outra coisa do que produto da sua essência espiritual.

Disso resulta uma primeira avaliação da negação da negação. Para Feuerbach, Hegel parte da religião, contrapõe-lhe o mundo real como negação e retorna pela negação da negação para a religião. Feuerbach revela com isso o falso positivismo de Hegel. Marx apreende aquilo que Feuerbach designa como negação e restabelecimento da religião, ainda que de modo mais universal, na medida em que ele relaciona ambos com a filosofia: "[...] a razão está [...] junto de si na não razão enquanto não razão" (131). A não razão enquanto não razão é a não razão sabida. Se ela é afirmada nesse saber, então ela tem seu lugar na razão. Isso é a "auto-asserção, autoconfirmação" da filosofia em "contradição consigo mesma" (131).

A conclusão de Marx reza: „Em Hegel a negação da negação não é, portanto, a confirmação da essência verdadeira [espiritual-material C.I.]" do homem pela "negação da essência aparente" [isto é, a essência espiritual abstratamente pensante C.I.], "da essência [verdadeira C.I] alienada de si em sua negação", mas "a confirmação da essência aparente" (131). À essência aparente espiritual deve ser tirada sua estranheza frente ao homem e, com isso, ocorrer "sua transformação no sujeito" (idem). O homem e a natureza são rebaixados a meros predicados do ideia-sujeito (cf. 133).

A filosofia de Hegel exerce apenas uma suprassunção teórica da alienação, que deixa existir a realidade alienada e ao mesmo tempo acredita tê-la superado, na medida em que ela é tomada como "autoconfirmação" (131) da autoconsciência pensante. Como crítica da alienação, ela permanece dentro da alienação, e precisamente tanto da alienação espiritual como também da alienação real.

Marx queria libertar a concepção de Hegel do sentido positivo da negação da negação da forma alienada em Hegel e pôr ao serviço da sua concepção materialista da história. Feuerbach não vê que a concepção de Hegel da negação da negação não exprime tão-

\begin{tabular}{|c|c|c|c|c|}
\hline Q Rovista Dialectus & Ano 5 & n. 12 & Janeiro - Julho 2018 & p. $121-138$ \\
\hline
\end{tabular}


somente o restabelecimento da filosofia em contradição consigo mesma, mas uma intelecção histórico-filosófica fundamental. Na Fenomenologia do Espírito, Hegel teria apreendido a essência do trabalho e, em segundo lugar, a estrutura principal da história humana sob as condições da alienação (cf. 123). ${ }^{18}$ A essência do trabalho consiste na exteriorização e suprassunção da exteriorização que é ao mesmo tempo uma autogeração histórica do homem, porque nela a essência genérica "homem" expõe e torna objetivo todas as suas forças essenciais. Antes que a apropriação de Marx da concepção hegeliana da negatividade seja iluminada, deve ser lançada sucintamente uma olhada a sua interpretação da lógica e da passagem da lógica para a natureza.

b. Ciência da Lógica: Como desempenho positivo da lógica hegeliana, Marx mantém firme três pontos: (i) as formas abstratas do pensar são, sem dúvida, produtos do espírito humano, mas assumem na perspectiva da auto-alienação espiritual a aparência de essencialidades auto-subsistentes que antecedem à natureza e ao espírito. Isso vai ao encontro da caracterização de Hegel da lógica como "apresentação de Deus, tal como Ele é em sua essência eterna antes da criação da natureza e de um espírito finito". ${ }^{19}$ (ii) As categorias do pensar são apresentadas na sua conexão sistemática e se tornam, com isso, „objeto da crítica“ (135). (iii) O processo do pensar não aparece „,como externação da essência do homem” (135), mas sob o nome da ideia se afirma como sujeito auto-subsistente. Com isso, Marx pôs em liberdade o caráter metafísico da lógica hegeliana, na qual os pensamentos especulativos assumem, por fim, um caráter formativo do mundo.

c. A passagem para a natureza e a filosofia real: Marx conhece a estrutura argumentativa da dedução hegeliana da natureza a partir da ideia. A natureza é, em primeiro lugar, algo além do que a ideia, o pensar. Ela é algo externo ao pensar, primariamente dado à sensibilidade. Esse ser outro, o ser exterior da natureza frente ao pensar é, contudo, tãosomente produto do pensar, pois ela é o ser externo a si mesmo do pensar, da ideia. A natureza não tem, portanto, em terceiro lugar, nenhuma subsistência essencial dentro de si. Ela tem que suprassumir-se e passar no outro de si mesmo, no espírito. Para Marx, ao contrário, a natureza tem sua determinação essencial própria, ela é primariamente objeto dos sentidos para o homem. Essa determinação não lhe é atribuída pelo pensar. No seu auto-

18 Com sua concepção da essência genérica humana que se efetiva historicamente, Marx mal entendeu a Fenomenologia do Espírito de Hegel como filosofia da história (cf. Arndt. Geschichte und Freiheitsbewusstsein [História e consciência da liberdade] (obs. 17, 52-59). A Fenomenologia é, antes, o desenvolvimento teórico de consciência dos resultados do trabalho histórico do espírito.

${ }^{19}$ G.W.F. Hegel. Ciência da Lógica 1. A Doutrina do Ser. Petrópolis, RJ: Vozes, 2016, 52.

\begin{tabular}{|l|l|l|l|l|}
\hline Q Ponista Qialectus & Ano 5 & n. 12 & Janeiro - Julho 2018 & p. 121-138 \\
\hline
\end{tabular}


abandono, o pensar abstrato depara-se, com efeito, com o limite da abstração, a natureza, mas apenas para retornar da sua exterioridade para si mesmo e alcançar no espírito seu ser para si.

\section{Negatividade, exteriorização e alienação}

Voltemos a falar sobre a apropriação crítica de Marx da concepção hegeliana da negação da negação e aprofundemos o dito. Primeiro: o que desempenha o modelo da exteriorização da atividade, ou seja, do trabalho, e segundo: como a exteriorização e a alienação se diferenciam? À diferença da externação - na qual o sujeito não se torna completamente externo a si, mas mantém seu caráter interior ainda distinto do exterior, com o qual ele ao mesmo tempo se relaciona - na exteriorização se trata de um esvaziamento completo do interior no exterior. De acordo com Marx, no seu trabalho o homem não se externa apenas, mas se exterioriza, na medida em que ele não reserva nada de sua essência e, assim, em sua exposição completa de sua essência, altera e consuma sua própria essência. $\mathrm{O}$ modelo da exteriorização e da objetivação do trabalho explica, nesse sentido, a perfectibilidade da autoefetivação histórica da essência genérica humana. ${ }^{20}$

A negação da negação com resultado positivo Marx abstrai, primeiramente, da estrutura da atividade do espírito em Hegel como exteriorização e retorno da exteriorização. Ao espírito é inerente uma tal dialética da negatividade, porque ele é atividade, e precisamente atividade sem substrato. Porque o espírito é atividade pura, ele pode efetivar-se apenas na história. Assim como o espírito somente há como história, a história há apenas

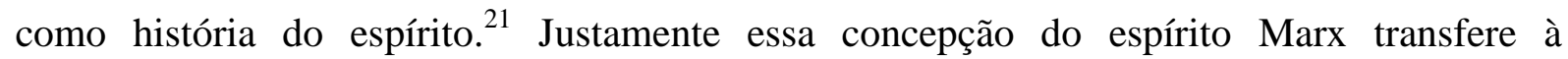
concepção assumida de Feuerbach e Moses Heß da essência genérica humana que se efetiva apenas historicamente. Com isso a estrutura da atividade do espírito como exteriorização e retorno da exteriorização é atribuída também à atividade do sujeito humano singular que é apreendida como negação da negação. A atividade individual, também a do trabalho, aponta para a autoefetivação. O trabalho, a poiesis como objetivação, como produção de objetos

20 O trabalho é como um ,ato de autoprodução do homem“ (132) ,auto-alienação. exteriorização da essência, desobjetivação e desefetivação do homem como auto-aquisição, externação da essência, objetivação, efetivação" (idem [tradução minha]). A consumação da essência se efetua via uma espécie de kenosis [esvaziamento].

21 Hegel se orienta pelo modelo básico "da dialética do espírito que se exterioriza e retorna para dentro de si. Ao espírito, como o tema abrangente da filosofia hegeliana, é inerente tal dialética, porque ele é história ou [...] atividade". (Michael Theunissen. Hegels Lehre vom absoluten Geist als theologisch-politischer Traktat [A doutrina do espírito absoluto como tratado teológico-político]. Berlin/New York 1970, 65s.).

\begin{tabular}{|c|c|c|c|c|}
\hline Rovista Dialectus & Ano 5 & n. 12 & Janeiro - Julho 2018 & p. $121-138$ \\
\hline
\end{tabular}


externos, é apreendido como exteriorização e como retorno da exteriorização, como apropriação e, com isso, como praxis. E é essa espécie da estrutura da atividade que Marx interpreta como negação da negação.

Quando a atividade dos sujeitos humanos é apreendida como negação da negação, isso é a expressão formal da estrutura invariante da atividade que insiste na autoefetivação histórica do homem. A negação da negação entende, porém, também algo diferente, precisamente a alienação social e a suprassunção dessa alienação. $\mathrm{O}$ texto nos confronta com o seguinte problema: Hegel frequentemente toma exteriorização por alienação, embora ele factualmente não a diferencie da exteriorização (aproximadamente quando ele conceitualiza a exteriorização do pensar na oposição sujeito-objeto ao mesmo tempo como alienação cf. 121). Em Marx ocorre o inverso: ele capta alienção como exteriorização (sobretudo quando ele localiza a „origem da propriedade privada“ (89) no „trabalho exteriorizado“ idem), não obstante ele conhece também uma alienação distinguida da exteriorização. Todas as formas da alienação (espiritual, política, econômico-material) estão enraizadas na auto-alienação do homem, que tem seu fundamento na alienação do trabalho pela propriedade privada. A autoalienação do homem se diferencia na alienação do trabalhador do seu próprio produto, na alienção do próprio trabalho, na alienação da sua essência genérica e na alienação do homen por outro homem (cf. 79-90). ${ }^{22}$

Como se distinguem a alienação e a exteriorização em Marx? O fato de que o trabalho produz um produto externo o define como exteriorização. O fato de que o produto se torna um alheio pela sua ocupação pela propriedade privada define a alienação. A conexão entre alienação e exteriorização consiste no fato de que em sua exteriorização a atividade é impedida no seu retorno para dentro de si mesma. A alienação separa, portanto, a conexão entre exteriorização e retorno. O tecido bem sucedido da vida dos sujeitos atuantes pressupõe, portanto, a suprassunção da alienação, da abolição da propriedade privada nos meios de produção.

Resumamos: Marx compreende a negação da negação histórica como alienação e suprassunção da alienação (apropriação) que, por sua vez, é compreendida a partir de uma

22 As determinações da alienação são conhecidas como fenômenos sociais: como expropriação, separação do trabalhador do seu produto de trabalho, como comportamento instrumental do trabalhador a sua atividade do trabalho, como determinação alheia do homem que trabalha na remuneração e organização do trabalho na oficina e como objetivação das relações sociais no troco mediado pelo dinheiro. A crítica visa à apropriação e autodeterminação da organização do processo de trabalho e seus resultados e o controle geral das relações sociais. Como alienação do homem elas aparecem a partir do ponto de vista de um essencialismo da essência genérica (efetivação da essência).

\begin{tabular}{|l|l|l|l|l|}
\hline Q Rovista Qialectus & Ano 5 & n. 12 & Janeiro - Julho 2018 & p. 121-138 \\
\hline
\end{tabular}


exteriorização e retorno da exteriorização apreendido como negação da negação, que como em Hegel é pensada como estrutura invariante da essência da atividade. O fato de que Hegel unicamente conhece e reconhece o trabalho "abstratamente espiritual" (124) deixa a compreender a Marx que Hegel concebe a atividade da exteriorização e do retorno da exteriorização, a dialética da negatividade, apenas como atividade sem substrato do espírito. Todiavia, a despeito da sua crítica à versão abstrata da negação da negação em Hegel $^{23}$, Marx mantém-se firme no conceito da negação da negação, porque ele quer se manter firme na atividade. Além da crítica está, portanto, também uma afirmação. Marx se move, portanto, ele mesmo nos moldes daquilo que criticou. O padrão de medida normativo da crítica à alienação real é a atividade pensada como negatividade. E precisamente Marx pensa atividade com Hegel como exteriorização e retorno, na medida em que ele mede toda a atividade nisso, mesmo que ele compreenda essa atividade como atividade objetiva, como trabalho, que não resulta na exteriorização de uma finalidade subjetiva. ${ }^{24}$

Marx acentua repentinamente que com sua teoria da negatividade da atividade Hegel apreende a essência do trabalho e, com isso, a autogeração histórica do homem pelo trabalho (cf. 118s, 123). Com a adoção da figura da negação da negação Marx assume também o resultado positivo que é o homem historicamente gerado. O resultado positivo da negação autorreferente é destacado expressamente com as expressões "auto-aquisição" e "efetivação" (132) do homem. Marx mantém-se firme de certo modo no conceito de Hegel do tornar-se espírito do homem pela exteriorização e retorno quando ele pensa a autogeração histórica do homem como autoefetivação.

23 Hegel liquefaz a ,atividade plena de conteúdo, viva, sensível, concreta da auto-objetivação“ (133) para a atividade sem substrato, da „negatividade absoluta“ (idem) do espírito, cujo "conteúdo [é] meramente formal, produzido pela abstração de todo o conteúdo" (idem). - Diferentemente de Marx, Kierkegaard se junta positivamente a Hegel assim que ele compreende o ser si-mesmo do homem como atividade sem substrato. Em virtude desse fim da auto-efetivação o ser si-mesmo do homem está despido de toda a prédeterminação e de todo o caráter de substrato. Como negação permanente da possibilidade da negatividade do desespero se aproxima da ato-ação [Tathandlung] fichteana, em que justamente se manifesta o ser posto do Si por Deus, porque no seu processo intensamente sem repouso o Si experimenta que ele não é capaz de libertar-se (cf. Michael Theunissen. Das Selbst auf dem Grund der Verzweiflung, [O Si no fundamento do desespero]. Frankfurt am Main: Anton Hain, 1991, 53-65).

24 Para os alicerces teóricos de agir de Marx cf. Lange. Das Prinzip Arbeit [O princípio do trabalho] (obs. 10). Lange tem a posição de "que o modelo da exteriorização, ou seja, a objetivação forma o recurso conceitual principal decisivo da crítica marxiana" (idem, 55). Já em Hegel a interpretação da ação como exteriorização, como transferência de uma finalidade subjetiva no objetivo externo seria problemática. Marx cansaria ainda essa tese, quando ele apreende o trabalho como exteriorização e o produto do trabalho como trabalho coalhado (idem, 20s.). No seu comentário para os Manuscritos parisienses (cf. obs. 12) Quante se junta à posição de Lange, sem examinar ulteriormente o problemático na teoria da exteriorização da atividade.

\begin{tabular}{|l|l|l|l|l|}
\hline Q Rovista Qialectus & Ano 5 & n. 12 & Janeiro - Julho 2018 & p. 121-138 \\
\hline
\end{tabular}


Bem visível é, contudo, a modificação decisiva da teoria hegeliana da negatividade que Marx efetua. Marx repreende à filosofia de Hegel um positivismo falso que objetiva a afirmação do existente. $\mathrm{O}$ ponto crítico decisivo à figura de Hegel da negação da negação é que ele tem um resultado que restabelece o início com a essência espiritual pensante. A espécie distinta do resultado positivo da negação da negação é para Marx tal que ela comparece num grau elevado. A suprassunção da propriedade privada nos meios de produção que se baseia no trabalho alheio ou alienado não restabelece novamente a propriedade privada que se baseia no trabalho próprio, mas conduz a uma forma elevada de propriedade, a propriedade social.

\section{Esboço da posição própria de Marx ${ }^{25}$}

Do positivismo falso da filosofia hegeliana Marx distingue um positivismo correto que ele assume de Feuerbach. Feuerbach contrapõe à negação da negação hegeliana um positivo que repousa sobre si mesmo, quer dizer, um positivo não dependente da negação, um positivo que antecede à negação da negação. O puro positivo é o dado sensível da natureza. Marx assume de Feuerbach também o pensamento da unidade do naturalismo e do humanismo, do materialismo e do idealismo, e nesses moldes ele interpreta o "verdadeiro materialismo" (118) (teórico social).

Ao mesmo tempo, Marx queria reportar o positivismo correto de Feuerbach à negação da negação hegeliana como sua pressuposição necessária. Ele faz isso, na medida em que ele inscreve no humanismo naturalista primeiramente o momento da atividade como negatividade.

O homem é uma essência objetiva, uma essência espiritual-natural que exerce uma "atividade objetiva" (127). ${ }^{26} \mathrm{O}$ conceito da atividade objetiva está dirigido contra a quimera hegeliana da pura atividade sem substrato do espírito. Como o "humanismo positivo" (132) o humanismo naturalista está mediado pela suprassunção da propriedade privada que alheia e, com isso, é idêntico ao "comunismo" (idem).

Com o conceito da atividade objetiva estão entendidas duas coisas distintas: (i) a atividade que produz objetos externos, quer dizer, o trabalho. À diferença da atividade sem

25 Cf. 126-128.

26 "Feuerbach quer objetos sensíveis efetivamente distintos dos objetos de pensamentos; mas ele não apreende a própria atividade humana como atividade objetiva" (Karl Marx. $1^{\text {a }}$ tese de Feuerbach. In: MEW 3, 533).

\begin{tabular}{|l|l|l|l|l|}
\hline Qevista Dialectus & Ano 5 & n. 12 & Janeiro - Julho 2018 & p. 121-138 \\
\hline
\end{tabular}


substrato do espírito, mas também da ação que resulta na realização subjetiva do fim, o trabalho está sob condições objetivas, dadas. Ele é uma realização subjetiva do fim como objetivação sob condições de objetividade dada. ${ }^{27}$

A objetividade fundamental da essência espiritual-natural, que é o homem, reside na sua sensibilidade e corporalidade, pelas quais ele se torna objeto de outros, um tu. Como essência espiritual-natural a essência humana é uma essência de deficiências, uma essência paciente e passional que depende da sociabilidade. Marx coloca a objetividade da essência genérica humana, com isso, ao mesmo tempo no contexto da sociedade e, com isso, da história. A tese antropológica inspirada por Feuerbach da essência genérica humana objetiva reza, portanto, o seguinte: o homem é essencialmente uma essência sensível, corpórea e social que se comporta teórica e praticamente consigo como gênero e se efetiva historicamente.

Com efeito, com a negatividade Hegel teria encontrado, como vimos, a expressão abstrata da história, mas a história efetiva do homem, que Hegel não acerta, é a de um sujeito pressuposto, com caráter de substrato, que Marx identifica com o positivo feuerbachiano como essência objetiva que o homem é enquanto essência espiritual-natural, cuja consumação está mediada historicamente.

O naturalismo humanista deve poder compreender a história, contudo, ele tem a tendência para o inverídico. Ele guarda o perigo de uma naturalização da libertação do homem da sua história natural, portanto, da história que se efetua sob as condições da alienação social. Marx pensa o tecido de vida individual como exteriorização e suprassunção da exteriorização assim que ele se efetua com necessidade de um processo natural e se faz valer normativamente como tal. Se a exteriorização do trabalho que se objetiva se dá sob as condições da alienação, então, o homem, que alveja a perfectibilidade de suas forças essenciais, tem o esforço de retornar para si pela suprassunção da alienação da sua exteriorização, de estar junto de si mesmo no seu trabalho. Isso é a meta da história como história natural.

Dois pontos de crítica ulteriores à concepção de Marx dos Manuscritos parisienses, de 1844, são pertinentes aqui: (i) A despeito da sua crítica ao trabalho alienado ao serviço da propriedade privada, Marx mantém firme sem exceção na sua avaliação positiva do trabalho como tal. A redução do trabalho pelo aumento da produtividade, a diminuição do tempo de trabalho etc. não é nenhum tema de suas considerações. O pensamento da

27 Cf. Arndt. "Karl Marx, Ökonomisch-philosophische Manuskripte. Kommentar von Michael Quante“ [recensão] (obs. 13), 204s.

\begin{tabular}{|l|l|l|l|l|}
\hline Q Rovista Dialectus & Ano 5 & n. 12 & Janeiro - Julho 2018 & p. 121-138 \\
\hline
\end{tabular}


suprassunção do trabalho pelo trabalho, precisamente pelo trabalho mais produtivo, é formulado apenas mais tarde. ${ }^{28}$ (ii) $\mathrm{O}$ discurso do homem e da sua essência forma um padrão de medida abstrato-filosófico à alienação espiritual e social. A alienação é a alienação do homem de si mesmo; sua suprassunção o retorno do homem para dentro de si mesmo. $\mathrm{O}$ capitalismo, assim a objeção, não corresponde à essência do homem, é hostil ao homem. Com isso justamente não é dito, em que o capitalismo concretamente é prejudicial para a qualidade da vida dos homens. Consequentemente, o comunismo está projetado como programação da salvação da humanidade. A superação do capitalismo ocorre, a fim de trazer o homem numa relação de correspondência consigo mesmo, com sua essência. Marx substitui no lugar do espírito hegeliano um sujeito, o gênero humano, que é igualmente um sujeito aparente como o espírito. $\mathrm{O}$ homem, a humanidade, a essência genérica humana não é nenhum sujeito. A teoria da alienação desencontra o capitalismo como objeto da crítica.

\section{Observações conclusivas: revolução como negação da negação?}

Resumamos: 1. No excurso sobre Hegel nos Manuscritos parisienses, de 1844, o tema de Marx é uma vinculação crítica ao conceito de Hegel da negatividade, da negação da negação. Marx compreende a negatividade com e contra Hegel como atividade da exteriorização e do retorno da exteriorização que é, ao mesmo tempo, o padrão de medida normativo da crítica da alienação do trabalho ao serviço da propriedade privada. Diferentemente de Hegel, Marx liga a estrutura da negatividade da atividade à atividade objetiva do trabalho do homem, que ele distingue da estrutura sem substrato da negatividade do espírito e do pensar abstrato na lógica, na qual Hegel se limita. Ao mesmo tempo, a teoria de Marx da negatividade está incorporada no humanismo naturalista assumido de Feuerbach, que aponta a tendência da naturalização da história, cuja lei é a da negação da negação com resultado positivo.

2. Marx liga o pensamento da auto-objetivação do homem pelo trabalho à autoprodução histórica do homem que almeja o desenvolvimento perfeito de suas forças essenciais. Praticamente deve ser suprassumida uma alienação social que consiste no fato de que a objetivação do trabalho no produto não pode ser a auto-objetivação do homem. $\mathrm{O}$

28 E precisamente no ano de 1845 na observação de Marx sobre o livro de Friedrich List Das nationale System der politischen Ökonomie [O sistema nacional da economia política]. Citado em Andreas Arndt. "Zum philosophischen Arbeitsbegriff: Hegel, Marx \& Co“. In: Klaus-M. Kodalle (Org.). Arbeit und Lebenssinn. Kritisches Jahrbuch der Philosophie. Beiheft 3/2001, 106.

\begin{tabular}{|c|c|c|c|c|}
\hline Qovista Dialectus & Ano 5 & n. 12 & Janeiro - Julho 2018 & p. $121-138$ \\
\hline
\end{tabular}


padrão de medida abstrato da crítica é a essência genérica do homem, que deve ser trazido em correspondência consigo. A fim de estabelecer as condições para isso, é preciso de uma revolução que suspende a estrutura de propriedade da sociedade burguesa, a negação da negação como suprassunção prática da alienação real. Hegel pensava a autoefetivação do homem apenas dentro da alienação, como ato de apropriação espiritual.

3. A interpretação de Marx da autoefetivação histórica do homem como autoobjetivação pelo trabalho é um essencialismo antropológico que tem a tendência do naturalismo, objetivismo e perfeccionismo. A isso se confronta a tese da transformação revolucionária das relações sociais como ato da liberdade comunitária que visa a uma convergência racional sobre a divisão social do trabalho e da satisfação dos carecimentos, nesse caso o trabalho necessário deve ter lugar sob condições o mais agradáveis possível. ${ }^{29} \mathrm{~A}$ suprassunção da alienação social é um acontecimento coletivo causado deliberadamente, que resulta da intelecção dos participantes no prejuízo sistematicamente necessário dos seus interesses. ${ }^{30}$ A suprassunção da figura alienada pela propriedade privada do mundo objetivo não pode ocorrer com necessidade de um processo natural, como Marx postula em $O$ Capital. Contudo, a essência genérica humana não é mais nenhum discurso em $O$ Capital. $\mathrm{O}$ pensamento de uma autossuperação de acordo com a lei do sistema capitalista que exprime na fórmula da negação da negação e que tem um resultado positivo é factualmente um recalcamento da história real e dos sujeitos atuantes com vontade e consciência. Esse pensamento acompanhou a história do marxismo desde o início. Sobretudo de forma negativa, como diagnóstico do colapso, ele está ainda a caminho. Como pensamento histórico-filósofo a negação da negação de Hegel é um mito do qual deveríamos nos despedir. ${ }^{31}$

\section{REFERÊNCIAS}

29 No Manifesto comunista (1848) é o discurso de uma ,associação, em que o desenvolvimento livre de cada um é a condição para o desenvolvimento livre de todos" (MEW 4, 482), em O Capital. Livro I Marx fala da "associação de homens livres" (Marx. O Capital. Livro I. São Paulo: Boitempo: 2013 (obs. 4), 214/1493).

30 Como Theunissen diagnostica, o „objetivismo da história“ impede Marx de pensar "liberdade comunicativa”. Contudo, essa não é a "meta da ação", mas a forma, na qual a revolução e a primeira instalação das relações sociais se efetuam (cf. Michael Theunissen. Schein und Sein. Zur kritischen Funktion der Hegelschen Logik [Aparência e ser. Para a função crítica da lógica hegeliana]. Frankfurt am Main: Suhrkamp, 1978, 483-486.

31 Na verdade, ao se despedir da negação da negação, se deveria deixar reinar uma preocupação. No contexto teórico a considero por uma figura sólida do pensar que mantém firme a passagem necessária de uma categoria para a seguinte. Despedir-se dela também nesse contexto marca o negativismo filosófico de Adorno e Theunissen.

\begin{tabular}{|c|c|c|c|c|}
\hline Rovista Dialectus & Ano 5 & n. 12 & Janeiro - Julho 2018 & p. $121-138$ \\
\hline
\end{tabular}


Arndt, Andreas. "Zum philosophischen Arbeitsbegriff [Para o conceito de trabalho filosófico]: Hegel, Marx \& Co“. In: Klaus-M. Kodalle (Org.). Arbeit und Lebenssinn. Eine aktuelle Herausforderung in historischer und systematischer Perspektive. Kritisches Jahrbuch der Philosophie. Beiheft 3/2001, 99-106.

Arndt, Andreas. "Karl Marx, Ökonomisch-philosophische Manuskripte. Kommentar von Michael Quante“ [recensão]. In: Hegel-Studien 45 (2010). Hamburg: Meiner, 2011, 202-208.

Arndt, Andreas. Geschichte und Freiheitsbewusstsein. Zur Dialektik der Freiheit bei Hegel und Marx [História e consciência da liberdade. Para a dialética da liberdade em Hegel e Marx]. Berlin: Eule der Minerva Verlag, 2015.

Hegel, G.W.F. Theorie-Werkausgabe in zwanzig Bänden. E. Moldenhauer, K.M. Michel (Orgs.). Frankfurt am Main: Suhrkamp, 1969s.

Iber, Christian. Elementos da teoria marxiana do capitalismo. Um comentário sobre o livro I de O Capital de Karl Marx. Porto Alegre: Editora fi, 2013.

Lange, Ernst Michael. Das Prinzip Arbeit. Drei metakritische Kapitel über Grundbegriffe, Struktur und Darstellung der ,Kritik der Politischen Ökonomie 'von Karl Marx [O princípio do trabalho. Três capítulos meta-críticos sobre conceitos fundamentais, estrutura e apresentação da , crítica da economia política' de Karl Marx]. Frankfurt am Main/Berlin: Ullstein, 1980.

Marx, Karl/Engels, Friedrich. Werke. 39 vol., 1 Ergänzungsband in 2 Teilen, 2 Verzeichnisse. Berlin (DDR) 1956s. (= MEW).

Marx, Karl. Manuscritos econômico-filosóficos. Tradução, apresentação e notas Jesus Ranieri. São Paulo: Boitempo, 2004.

Marx, Karl. O Capital. Crítica da economia política. Livro I. O processo de produção do capital. Tradução Rubens Enderle. São Paulo: Boitempo, 2013 (E-book).

Mészáros, István. Marx’s Theory of Alienation. London: Merlin Press, 1970.

Quante, Michael. Karl Marx, Ökonomisch-philosophische Manuskripte. Kommentar von Michael Quante. Frankfurt am Main: Suhrkamp, 2009.

Quante, Michael. „'Die Logik ist das Geld des Geistes'. Zur Rezeption der Hegelschen Logik im Linkshegelianismus und der Kritik der politischen Ökonomie" ["“A lógica é o dinheiro do espírito'. Para a recepção da lógica hegeliana na esquerda hegeliana e da crítica da economia política"]. In: Claudia Wirsing, Anton Friedrich Koch, Friederike Schick, Klaus Vieweg (Orgs.). Hegel - 200 Jahre Wissenschaft der Logik. Hamburg: Meiner, 2014, 413-431.

Theunissen, Michael. Hegels Lehre vom absoluten Geist als theologisch-politischer Traktat [A doutrina do espírito absoluto como tratado teológico-politico]. Berlin/New York: De Gruyter, 1970.

\begin{tabular}{|c|c|c|c|c|}
\hline Q Rovista Dialectus & Ano 5 & n. 12 & Janeiro - Julho 2018 & p. $121-138$ \\
\hline
\end{tabular}


Theunissen, Michael. Schein und Sein. Zur kritischen Funktion der Hegelschen Logik [Aparência e ser. Para a função crítica da lógica hegeliana]. Frankfurt am Main: Suhrkamp, 1978.

Theunissen, Michael. Das Selbst auf dem Grund der Verzweiflung. Kierkegaards negativistische Methode [O Si no fundamento do desespero. O método negativista de Kierkegaard]. Frankfurt am Main: Anton Hain, 1991.

\begin{tabular}{|l|l|l|l|l|}
\hline Rovista Dialectus & Ano 5 & n. 12 & Janeiro - Julho 2018 & p. 121-138 \\
\hline
\end{tabular}

